\title{
Protein synthesis-dependent long-term memory induced by one single associative training trial in the parasitic wasp Lariophagus distinguendus
}

\author{
Jana Collatz, ${ }^{1,3}$ Caroline Müller, ${ }^{2}$ and Johannes L.M. Steidle ${ }^{1}$ \\ ${ }^{1}$ Institut für Zoologie, Fachgebiet Tierökologie, Universität Hohenheim, 70593 Stuttgart, Germany; ${ }^{2}$ Lehrstuhl für Botanik II, \\ Universität Würzburg, 97082 Würzburg, Germany
}

\begin{abstract}
Protein synthesis-dependent long-term memory in Apis mellifera and Drosophila melanogaster is formed after multiple trainings that are spaced in time. The parasitic wasp Lariophagus distinguendus remarkably differs from these species. It significantly responds to the artificial odor furfurylheptanoate ( $F F H)$ in olfactometer experiments, when this odor was presented during one single training trial, consisting of one sequence of host recognition behavior on a wheat grain infested by its hosts. Feeding wasps with actinomycin D erases the learned response $24 \mathrm{~h}$ after the training, demonstrating that protein synthesis-dependent long-term memory has been formed in $L$. distinguendus already after one single training.
\end{abstract}

Parasitic wasps are hymenopterous insects, which develop on or in the body of other animals, mostly insects, thereby killing their hosts (Lafferty and Kuris 2002). Many species use chemical cues, associated with the host or the hosts' food plant to locate and recognize hosts for oviposition. Especially in generalist parasitoid species, these cues are often highly variable and not predictable (Vet et al. 1995), which prevents their innate use and favors the ability to learn. In fact, many parasitic wasps learn associatively to respond to stimuli they have perceived in the presence of hosts or food (Turlings et al. 1993; Vet et al. 1995). A recent review revealed that the learning of host-associated chemicals has been demonstrated for over 30 parasitic wasp species (Steidle and van Loon 2003).

Despite the abundance of publications on learning in parasitic wasps, few attempts have been made to compare learning in parasitic wasps with current knowledge about the model insects for memory structure and learning, Drosophila melanogaster Meigen (Diptera, Drosophilidae) and Apis mellifera L. (Hymenoptera, Apidae) (e.g., Kaiser et al. 2003; Takasu and Lewis 2003). Specifically, there are no conclusive studies on the memory structure in parasitic wasps. In honeybees, different phases of memory are known, including two sequential forms of long-term memory. The early form (early long-term memory, eLTM) at the range of 24-48 $\mathrm{h}$ after the training is translation dependent, whereas the later form (late long-term memory, ILTM) starts after about $48 \mathrm{~h}$, depends on transcription (Menzel 1999; Müller 2002), and requires several spaced training events (Menzel et al. 2001). Likewise, in Drosophila, two forms of longer-lasting memories exist, so-called amnesia-resistant memory (ARM) and long-term memory (LTM), differing in duration and dependence on protein synthesis (Tully et al. 1994).

To study protein-dependent long-term memory in parasitic wasps in more detail, the present study was carried out with the pteromalid wasp Lariophagus distinguendus Förster as a model organism. This species is an ectoparasitoid of immature stages of the granary weevil Sitophilus granarius L. living in wheat grains (Steidle and Schöller 1997). A recent study has shown that the

\footnotetext{
${ }^{3}$ Corresponding author.

E-mail collatz@gmail.com; fax 49-711-4593814.

Article and publication are at http://www.learnmem.org/cgi/doi/10.1101/ Im.192506.
}

ability of these wasps to associate the artificial odorous compound furfurylheptanoate (FFH) with host presence. The learned response is maintained for at least $6 \mathrm{~d}$, indicating that long-term memory is formed (Müller et al. 2006). So far, the behavior during which $L$. distinguendus forms the association is unknown. In encounters with host-infested grains, wasps perform a more or less stereotypic behavioral sequence of host recognition (Steidle 2000). At first, females antennate the surface of the grain (drumming). When chemical cues on the grain surface indicate the presence of a host, females bend their abdomen and tap on the grain surface with their abdominal tip, where the tip of the ovipositor is also situated (tapping). Once a suitable place is found, the ovipositor is drilled into the grain (drilling). In the grain, wasps use the ovipositor to locate the host in the grain, palpate the host, and finally lay an egg on its outside (J.L.M. Steidle, J. Reinhard, K. Hörsch, M. v. Fragstein, and M. Stöffler, unpubl.).

The present study aims (1) to determine during which part of the host-encounter process associative learning occurs in $L$. distinguendus, (2) to study the duration of the induced memory, and (3) to test whether the formation of this memory is proteinsynthesis dependent.

Insect cultures were kept at $25^{\circ} \mathrm{C}, 30 \%$ r.h., and a photoperiod of 16:8 h (L:D). Larvae of $S$. granarius (3rd-4th instar) in wheat grains (Triticum aestivum L., 14\% moisture content) were used as host for L. distinguendus. This host age is known to be optimal for parasitization by L. distinguendus (van den Assem 1971).

Parasitoids were trained $2 \mathrm{~d}$ after emergence and were tested at certain intervals afterward. For training, wasps were released in Petri dishes (diameter, $9 \mathrm{~cm}$ ) with $30 \mathrm{~S}$. granaries-infested wheat grains and a glass capillary $(2 \mathrm{~cm}$, diameter, $1.56 \mathrm{~mm}$ ) containing pure furfurylheptanoate (FFH, Sigma-Aldrich). The capillary was fixed in a block of paraffin $(1.5 \times 1.5 \times 1.5 \mathrm{~cm})$, allowing the FFH to evaporate from one end. The artificial volatile substance FFH was chosen to avoid any potential pre-adaptation by the parasitoids. Depending on the experiment, different training procedures were used. Wasps were allowed to either (1) drum with their antennae on the infested grains for $10 \mathrm{sec}$ or, (2) to perform one sequence of host-recognition behavior consisting of drumming, tapping, and drilling with their ovipositor into a grain. Wasps were removed after they had withdrawn their ovipositor. To analyze the frequency and duration of the different 
host-recognition behaviors during the training, the behavior of 20 wasps was recorded using the program "The Observer 5.0" (Noldus). After training, wasps were kept solitary until testing in Eppendorf vials with moistened filter paper, and closed with cotton wool. Twenty wasps were tested for each experiment.

At 1, 24, or $48 \mathrm{~h}$ after training, the response of the wasps toward FFH was tested in an olfactometer (Fig. 1). This is made of heat-resistant synthetic material and consists of a cylinder $(4-\mathrm{cm}$ high, diameter, $19 \mathrm{~cm}$ ) divided by vertical plates into four chambers. On the top of the cylinder, a walking arena $(1-\mathrm{cm}$ high, diameter, $19 \mathrm{~cm}$ ) is placed, which consists of metal gauze (mesh, $0.5 \mathrm{~mm})$ with a rim of heat-resistant synthetic material $(0.9-\mathrm{cm}$ high), and covered with a glass plate. No airflow is generated. A glass capillary $(2 \mathrm{~cm}$, diameter, $1.56 \mathrm{~mm}$ ) containing pure FFH or a Petri dish containing $1 \mathrm{~g}$ wheat grains infested by 3rd-4th instar larvae of $S$. granarius were placed in one chamber (test chamber). The opposite chamber remained empty (control chamber). The olfactometer was illuminated from above. At the beginning of each experiment, an Eppendorf vial containing one wasp was placed in the center of the walking arena. The cotton wool plug was removed and the wasp entered the arena uninfluenced by the observer. Each wasp was tested only once. The behavior (walking, resting) and the position of the wasp were recorded for 600 sec using the computer software "The Observer 5.0" (Noldus, Wageningen). To avoid biased results due to side preferences, the position of the olfactometer was rotated clockwise after every wasp. The time the wasp spent walking in the field of the walking arena above the test chamber with FFH (test field) or in the opposite field (control field) was analyzed with the Wilcoxonmatched pairs test using the software package Statistica for Windows 4.5 (StatSoft Inc. 1993).

To examine whether protein synthesis-dependent longterm memory is formed after one single training experience, wasps were continuously fed actinomycin D from $24 \mathrm{~h}$ before training until testing. This was done by placing a piece of filter paper $(0.8 \times 2 \mathrm{~cm})$ soaked with $20 \mu \mathrm{L}$ of actinomycin D-sugar water solution (1 mM actinomycin D in $20 \mathrm{mg} / \mathrm{mL}$ sugar water) into the Eppendorf vial, where single wasps were kept. For training, wasps were allowed to perform the full behavioral sequence as described above. Then, wasps were tested in the olfactometer for their response to FFH after intervals of 12 and $24 \mathrm{~h}$. Control wasps were treated identically, but were only fed sugar water without actinomycin D. To exclude the possibility that actinomycin D affects learning ability in general, a third group of wasps were fed with actinomycin $\mathrm{D}$ for $48 \mathrm{~h}$, then trained by performing a host-recognition sequence in the presence of $\mathrm{FFH}$, and were tested in the olfactometer $1 \mathrm{~h}$ later for their response to FFH. Twenty wasps were tested for each experiment.

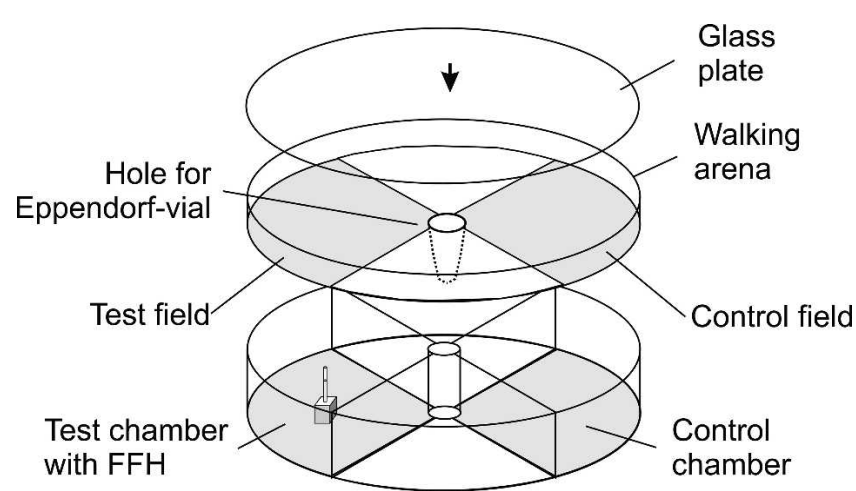

Figure 1. Olfactometer for testing the response of wasps toward FFH or toward infested grains.
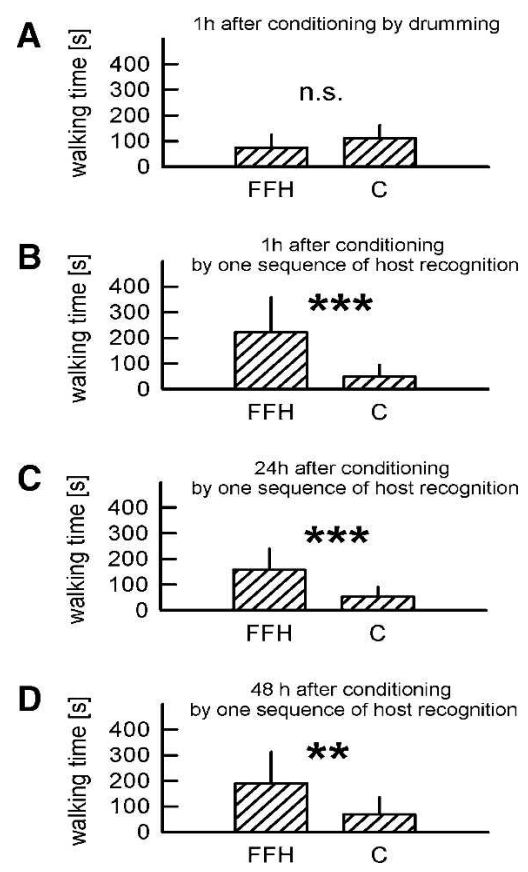

Figure 2. Walking time (mean $\pm \mathrm{SD} ; n=20$ ) of differently conditioned females of Lariophagus distinguendus in the odor fields of an olfactometer, with one field containing odor of FFH and the other left empty as control (C). (A) Females that were allowed to drum for $10 \mathrm{sec}$ on infested grains in the presence of $\mathrm{FFH}$ and were tested $1 \mathrm{~h}$ later. (B) Females that were allowed to perform one behavioral sequence of host recognition up to drilling into infested grains in the presence of $\mathrm{FFH}$ and were tested $1 \mathrm{~h}$ later. (C) Females that were trained as in $B$ and were tested $24 \mathrm{~h}$ later. $(D)$ Females that were trained as in $B$ and were tested $48 \mathrm{~h}$ later. (n.s.) Not significant; ${ }^{* *} P<0.01 ;{ }^{* * *} P<0.001$ (Wilcoxon-matched pairs test).

Wasps that had only drummed on the infested grains during training did not show any difference in walking time in the test field with FFH as compared with the control field in the olfactometer (Fig. 2A). In contrast, wasps that performed one single sequence of host recognition behavior up to drilling preferred the odor field with FFH significantly to the control field. This preference was found at 1, 24, and $48 \mathrm{~h}$ after the training (Fig. 2B-D).

The behavioral sequence of host recognition up to the first drilling takes about $195 \mathrm{sec}( \pm 116$; mean \pm s.d., $n=20)$. It consists of $1.3( \pm 0.7)$ drumming events, lasting for about $105 \mathrm{sec}$ ( \pm 74$)$, followed by $1.1( \pm 0.3)$ tappings, and drilling for about 51 sec $( \pm 52)$. Because the first sequence of host recognition by wasps on a newly encountered grain is required to locate the host (J. Steidle, J. Reinhard, K. Hörsch, M. v. Fragstein, and M. Stöffler, unpubl.), oviposition did not occur during the training.

To test whether one single training consisting of one host recognition sequence in the presence of FFH induces protein synthesis-dependent long-term memory, wasps were fed actinomycin D before and after training (Wüstenberg et al. 1998). Twelve hours after training, wasps that were fed actinomycin D (Fig. 3B), as well as control wasps, were significantly attracted to FFH (Fig. $3 \mathrm{~A})$. In contrast, at $24 \mathrm{~h}$ after the training, only control wasps showed a response to FFH (Fig. 3C,D). Wasps that were fed actinomycin $\mathrm{D}$ for $48 \mathrm{~h}$ and were trained $1 \mathrm{~h}$ afterward strongly responded to FFH in the olfactometer (Fig. 3E). Thus, actinomycin $\mathrm{D}$ does not prevent learning and strong olfactory responses in L. distinguendus.

The present study demonstrates that after one sequence of host recognition on infested grains in the presence of the artificial odor FFH, females of $L$. distinguendus prefer this odor in subsequent olfactometer experiments. Drumming on infested grains

\section{Learning \& Memory}

www.learnmem.org 
A



B

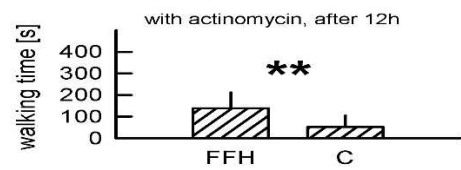

C

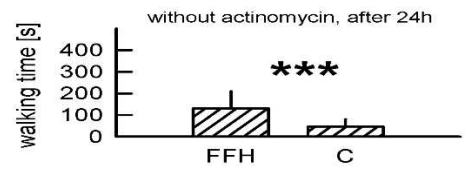

D

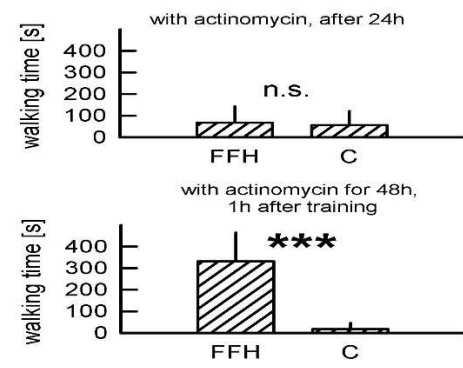

Figure 3. Walking time (mean $\pm S D ; n=20$ ) of differently conditioned females of Lariophagus distinguendus in the odor fields of an olfactometer, with one field containing odor of FFH and the other left empty as control (C). (A) Females that were fed with sugar water before conditioning and tested $12 \mathrm{~h}$ later. $(B)$ Females that were fed actinomycin $D$ in sugar water before conditioning and tested $12 \mathrm{~h}$ later. (C) Females that were fed with sugar water before conditioning and tested $24 \mathrm{~h}$ later. $(D)$ Females that were fed with actinomycin $D$ in sugar water before conditioning and tested $24 \mathrm{~h}$ later. $(E)$ Females that were fed with actinomycin D in sugar water for $48 \mathrm{~h}$, conditioned, and tested for their response to FFH after 1 h. (n.s.) Not significant; ${ }^{* *} P<0.01 ;{ }^{* *} P<0.001$ (Wilcoxon-matched pairs test).

in the presence of FFH did not induce a preference. An earlier study has demonstrated that a response to FFH does not occur in naive wasps without any training, in wasps exposed to infested grains in the absence of FFH, or in wasps exposed to FFH in the absence of infested grains (Müller et al. 2006). Thus, in the experiments presented here, wasps must have associatively learned to respond to FFH during one single host-recognition sequence before the actual oviposition. This is in contrast to most other parasitic wasp species, where associative odor learning in the context of host finding has already been demonstrated after some seconds of drumming on host-associated chemicals (e.g., Geervliet et al. 1998; Fukushima et al. 2001; Meiners et al. 2003) or after oviposition (e.g., Geervliet et al. 1998; Takasu and Lewis 2003). Only Brachymeria intermedia seems to be similar to L. distinguendus, as in this species drilling, but not oviposition was required for associative learning (Kerguelen and Cardé 1996). Thereby, the authors assume that an association is formed between host stimuli and the arousal caused by drilling. Furthermore, learning in this species is considered to be a gradual process, increasing with raised experience (Kerguelen and Cardé 1995) rather than being induced by a single learning trial, as it could be demonstrated in L. distinguendus.

The learned response to FFH was maintained for at least 48 $\mathrm{h}$. This indicates that the training procedure used induces longterm memory, analogous to the protein synthesis-dependent ILTM in the honeybee (Menzel et al. 2001), and LTM in Drosophila (Tully et al. 1994) and other animals (DeZazzo and Tully
1995). To test this hypothesis, L. distinguendus females were fed with actinomycin $\mathrm{D}$, a transcription blocker, to prevent protein synthesis and the establishment of a potential long-term memory. This treatment led to the absence of a response to FFH after $24 \mathrm{~h}$. Obviously, when L. distinguendus females perceive FFH during host recognition, a protein synthesis-dependent associative long-term memory is formed after $24 \mathrm{~h}$. This result is remarkable for at least two reasons. First, as mentioned above, in honeybees, eLTM occurs between 24 and $48 \mathrm{~h}$ and transcriptiondependent ILTM, which can be blocked by actinomycin D, starts after $48 \mathrm{~h}$ (Menzel 2001). In our study, memory was already blocked by actinomycin $\mathrm{D}$ after $24 \mathrm{~h}$, indicating that in $L$. distinguendus, the equivalent to ILTM occurs at a time when, in the honeybee, eLTM is active. Thus, timing of memory phases differs between insects from the same order. Second, protein synthesisdependent LTM in animals, e.g., Drosophila (Tully et al. 1994), honeybee (Menzel et al. 2001), and mouse (Scharf et al. 2002) requires multiple trainings, which are spaced in time. In the honeybee, four conditionings with intertrial intervals of 10 min were used to induce ILTM (Menzel et al. 2001). Drosophila was trained 10 times with 15-min intertrial intervals to induce protein synthesis-dependent LTM (Tully et al. 1994). In contrast, only one training trial consisting of one sequence of host-recognition behavior lasting between 3 and 4 min was required to induce LTM in $L$. distinguendus. Even if the different behavioral elements (drumming, tapping, drilling) of one host-recognition sequence might represent some kind of multiple training, the continuous host-recognition sequence in the presence of FFH cannot be considered as spaced training. Thus, the formation of protein synthesis-dependent LTM in the parasitic wasp $L$. distinguendus is faster than in the honeybee, Drosophila, and other animals, e.g., mouse (Scharf et al. 2002). A recent study demonstrates memory lasting for $5 \mathrm{~d}$ after one single training in another parasitic wasp also, Cotesia glomerata (Bleeker et al. 2006). Thus, a natural memory-enhancing process occurs in $L$. distinguendus and possibly other parasitic wasps. The question, whether this mechanism involves CREB proteins as indicated by studies with transgenic Drosophila (Yin et al. 1995; Perazzona et al. 2004) and rats using vector-mediated gene transfer (Josselyn et al. 2001), or other mechanisms, is currently addressed by us.

Menzel $(1999,2001)$ proposed the hypothesis that the dynamics of memory formation in a species is adapted to the requirements of foraging of an animal species under natural conditions. According to this concept, early memory phases (shortterm and mid-term memory) in the honeybee are important during foraging for flowers when choices have to be made within patches, between patches, and between foraging bouts (Menzel 2001). Long-term memory for flower odors or colors is only established after one type of flower was repeatedly discovered as rewarding in different patches (Menzel 1999). In the case of $L$. distinguendus and C. glomerata, hosts occur aggregated in patches, often large enough to provide hosts for one female to lay all of the eggs it produces during its lifetime. Therefore, already during the first encounter with a host, the females perceive cues, which reliably indicate host presence for the rest of their lives. Under these conditions, the establishment of a LTM for host-associated cues after one single host contact might be more adaptive than LTM, which requires several spaced encounters, as in the honeybee.

This comparison between honeybee and L. distinguendus provides evidence in support of the hypothesis that memory dynamics are adapted to the ecology of a species (Menzel 2001). However, much more work is required to prove this idea. Thereby, parasitoid species are perfect model organisms, as this group of insects provides taxonomically related species with different ecology, which should be reflected in their memory dy- 
namics. Furthermore, these studies might provide new insights into the molecular mechanisms of memory formation.

\section{References}

Bleeker, M.A.K., Smid, H., Steidle, J.L.M., Kruidhof, M., van Loon, J.J.A., and Vet, L.E.M. 2006. Differences in memory dynamics between two closely related parasitoid wasp species. Anim. Behav. (in press).

DeZazzo, J. and Tully, T. 1995. Dissection of memory formation: From behavioural pharmacology to molecular genetics. Trends Neurosci. 18: $212-218$.

Fukushima, J., Kainoh, Y., Honda, H., and Takabayashi, J. 2001. Oviposition experience on host-infested plant affects flight and antennal searching behavior of Cotesia kariyai toward the host-plant complex. Entomol. Exp. Appl. 7: 251-256.

Geervliet, J.B.F., Ariens, S., Dicke, M., and Vet, L.E.M. 1998 Long-distance assessment of patch profitability through volatile infochemicals by the parasitoids Cotesia glomerata and C. rubecula (Hymenoptera: Braconidae). Biol. Control 11: 113-121.

Josselyn, S.A., Chanjun, S., Carlezon Jr., W.A., Neve, R.L., Nestler, E.J., and Davies, M. 2001. Long term memory is facilitated by cAMP response element-binding protein overexpression in the amygdala. $J$. Neurosci. 21: 2404-2412.

Kaiser, L., Perez-Maluf, R., Sandoz, J.C., and Pham-Delegue, M.H. 2003. Dynamics of odour learning in Leptopilina boulardi, a hymenopterous parasitoid. Anim. Behav. 66: 1077-1084.

Kerguelen, V. and Cardé, R.T. 1995. Increased host acceptance in experienced females of the parasitoid Brachymeria intermedia. Which types of oviposition behaviour contribute to experience? Entomol. Exp. Appl. 78: 95-103.

- 1996. Reinforcement mechanisms of olfactory conditioning during parasitization by the parasitoid Brachymeria intermedia (hymenoptera: Chalcididae). I. Insect Behav. 9: 947-960.

Lafferty, K.D. and Kuris, A.M. 2002. Trophic strategies, animal diversity and body size. Trends Ecol. Evol. 17: 507-513.

Meiners, T., Wäckers, F., and Lewis, W.J. 2003. Associative learning of complex odours in parasitoid host location. Chem. Senses 28: $231-236$

Menzel, R. 1999. Memory dynamics in the honeybee. J. Comp. Physiol. [A] 185: 323-340.

. 2001. Behavioral and neural mechanisms of learning and memory as determinants of flower constancy. In: Cognitice ecology of pollination. Animal behavior and floral evolution, (eds. L. Chittka and J.D. Thomson) pp. 21-40. Cambridge University Press, Cambridge, UK.

Menzel, R., Manz, G., Menzel, R., and Greggers, U. 2001. Massed and spaced learning in honeybees: The Role of CS, US, the intertrial interval, and the test interval. Learn. Mem. 8: 198-208.

Müller, U. 2002. Learning in honeybees: From molecules to behaviour. Zoology 105: 313-320.

Müller, C., Collatz, J., Wieland, R., and Steidle, J.L.M. 2006. Associative learning and memory duration in the parasitic wasp Lariophagus distinguendus. Anim. Biol. (in press).

Perazzona, B., Isabel, G., Preat, T., and Davis, R.L. 2004. The role of cAMP response element-binding protein in Drosophila long-term memory. J. Neurosci. 24: 8823-8828.

Scharf, M.T., Woo, N.H., Latal, M., Young, J.Z., Nguyen, P., and Abel, T. 2002. Protein synthesis is required for the enhancement of long-term potentiation and long-term memory by spaced training. J. Neurophysiol. 87: 2770-2777.

- 2000. Host recognition cues of the granary weevil parasitoid Lariophagus distinguendus (Hymenoptera: Pteromalidae). Entomol. Exp. Appl. 95: 185-192.

Steidle, J.L.M. and Schöller, M. 1997. Olfactory host location and learning in granary weevil parasitoid Lariophagus distinguendus (Hymenoptera: Pteromalidae). J. Insect Behav. 10: 331-342.

Steidle, J.L.M. and van Loon, J.J.A. 2003. Dietary specialization and infochemical use in carnivorous arthropods: Testing a concept. Entomol. Exp. Appl. 108: 133-148.

Takasu, K. and Lewis, W.J. 2003. Learning of host searching cues by the larval parasitoid Microplitis croceipes. Entomol. Exp. Appl. 108: 77-86.

Tully, T., Preat, T., Boynton, S.C., and Del Vecchio, M. 1994. Genetic dissection of consolidated memory in Drosophila. Cell 79: 35-47.

Turlings, T.C.J., Wäckers, F.L., Vet, L.E.M., Lewis, W.J., and Tumlinson, J.H. 1993. Learning of host-finding cues by hymenopterous parasitoids. In: Insect learning, (eds. D.R. Papaj and A.C. Lewis), pp. 51-78. Chapman \& Hall, New York.

Van den Assem, J. 1971. Some experiments on sex ratio and sex regulation in the pteromalid Lariophagus distinguendus Neth. J. Zool. 21: $373-402$.

Vet, L.E.M., Lewis, W.J., and Cardé, R.T. 1995. Parasitoid foraging and learning. In: Chemical ecology of insects 2, (eds. R.T. Cardé and W.J. Bell), pp. 65-101, Chapman \& Hall, New York.

Wüstenberg, D., Gerber, B., and Menzel, R. 1998. Long- but not medium-term retention of olfactory memories in honeybees is impaired by actinomycin D and anisomycin. Eur. J. Neurosci. 10: $2742-2745$.

Yin, J.C.P., Yin, J., Del Vecchio, M., Zhou, H., and Tully, T. 1995. CREB as a memory modulator: Induced expression of dCREB2 activator isoform enhances long-term memory in Drosophila. Cell 81: $107-115$.

Received November 2, 2005; accepted in revised form March 17, 2006.

\section{Learning \& Memory}






\section{Protein synthesis-dependent long-term memory induced by one single associative training trial in the parasitic wasp Lariophagus distinguendus}

Jana Collatz, Caroline Müller and Johannes L.M. Steidle

Learn. Mem. 2006, 13:

Access the most recent version at doi:10.1101//m.192506

References This article cites 19 articles, 3 of which can be accessed free at: http://learnmem.cshlp.org/content/13/3/263.full.html\#ref-list-1

License

Email Alerting

Receive free email alerts when new articles cite this article - sign up in the box at the Service top right corner of the article or click here. 